\title{
Changes in vitamin $\mathrm{D}$ and calcium metabolism markers in patients undergoing adjuvant chemotherapy for breast cancer
}

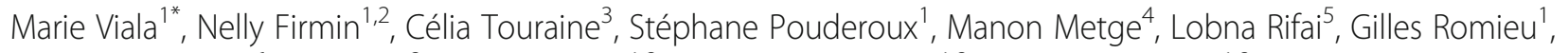
Hélène de Forges ${ }^{6}$, Lise Roca ${ }^{3}$, Séverine Guiu ${ }^{1,2}$, Véronique D'Hondt ${ }^{1,2}$ and William Jacot ${ }^{1,2}$

\begin{abstract}
Background: Changes in calcium metabolism and calcium urinary excretion during chemotherapy have not been thoroughly assessed in patients with early breast cancer (EBC), a population who frequently present vitamin $D$ insufficiency. As hypercalciuria is a classical contra-indication to vitamin D (VD) supplementation, this study evaluated changes in VD and calcium metabolism parameters in patients with EBC undergoing adjuvant chemotherapy (CT).

Methods: In patients with EBC who received six cycles of adjuvant CT, VD and calcium parameters were monitored at inclusion, and then every 3 weeks, at each $C T$ cycle initiation. The primary endpoint was the percentage of patients showing hypercalciuria during adjuvant CT (between Day 1, Cycle 1 [D1C1] and Day 1, Cycle 6 [D1C6]).

Results: The primary endpoint could be evaluated in 82 patients. Most patients ( $n=66,80.5 \%$ ) had VD insufficiency $(<$ $30 \mathrm{ng} / \mathrm{mL}$ ) at baseline. Hypercalciuria was detected in 29 patients (35.4\%; 95\% Cl: 25.6-46.5) between D1C1 and D1C6, but was not clinically significant in any of the affected patients. The percentage of hypercalciuria events was not different between patients with sufficient and insufficient baseline VD levels (34.8\% vs. 37.5\%), and between patients who received or not VD supplementation (37.5\% vs. $34.5 \%$,).

Conclusions: This comprehensive study on VD and calcium parameter changes in patients with EBC during adjuvant chemotherapy shows that hypercalciuria is a frequent abnormality in this setting, although asymptomatic. Therefore, it should not be considered as a limitation for high dose VD supplementation in this population.
\end{abstract}

Trial registration: EudraCT:2014-A01454-43. Registered 29 august 2016.

Keywords: Hypercalciuria, Vitamin D deficiency, Adjuvant chemotherapy, Breast cancer

\section{Background}

Breast cancer remains a major public health issue with a prevalence of 1700,000 new cases per year worldwide, and 522,000 deaths in 2012 [1]. Most breast cancers are diagnosed at an early stage, with a 5 -year survival rate of at least $99 \%$ for patients with localized tumors (tumor

\footnotetext{
* Correspondence: marie.viala@icm.unicancer.fr

'Department of Medical Oncology, Institut du Cancer de Montpellier (ICM), University of Montpellier, 208 avenue des Apothicaires, 34090 Montpellier, France

Full list of author information is available at the end of the article
}

size $<2 \mathrm{~cm}$ and no nodal invasion), but only of $85 \%$ for patients with axillary nodal invasion. In early-stage breast cancer (EBC), breast-conserving surgery or mastectomy with lymph node evaluation (sentinel lymph node resection or axillary lymph node dissection) is the milestone of the treatment strategy [2]. The indication of adjuvant systemic treatments (chemotherapy and endocrine therapies) relies on the tumor clinical and pathological characteristics.

Standard chemotherapy is based on the combination of anthracycline and taxanes [3]. In patients with HER2-

(C) The Author(s). 2021 Open Access This article is licensed under a Creative Commons Attribution 4.0 International License, which permits use, sharing, adaptation, distribution and reproduction in any medium or format, as long as you give appropriate credit to the original author(s) and the source, provide a link to the Creative Commons licence, and indicate if changes were made. The images or other third party material in this article are included in the article's Creative Commons licence, unless indicated otherwise in a credit line to the material. If material is not included in the article's Creative Commons licence and your intended use is not permitted by statutory regulation or exceeds the permitted use, you will need to obtain permission directly from the copyright holder. To view a copy of this licence, visit http://creativecommons.org/licenses/by/4.0/ The Creative Commons Public Domain Dedication waiver (http://creativecommons.org/publicdomain/zero/1.0/) applies to the data made available in this article, unless otherwise stated in a credit line to the data. 
overexpressing tumors, trastuzumab is administered in addition to chemotherapy for 1 year [4]. Adjuvant chemotherapy, its complications (such as chemotherapyinduced menopause), and the often associated corticosteroids may lead to modifications of the phosphoruscalcium balance and bone metabolisms [5], and consequently to adverse events, such as osteoporosis and associated fractures [6]. Moreover, vitamin D insufficiency is frequently observed in patients with $\mathrm{EBC}[7,8]$. For instance, in a previous study, we reported that in a sample of 77 patients with EBC treated with neoadjuvant chemotherapy, $79.5 \%$ had baseline vitamin D insufficiency and $97.4 \%$ at treatment end [5]. Therefore, calcium and vitamin D supplements are indicated in this population. However, the recommended dosages (400$500 \mathrm{IU} /$ day of vitamin D and $1 \mathrm{~g}$ of calcium) do not correct these deficiencies [9-11]. In agreement, Jacot and al suggested that higher doses of vitamin $\mathrm{D}$ and calcium are needed to improve vitamin $\mathrm{D}$ and calcium deficiency in patients with EBC ([12]). Moreover, no data is available on the changes in phosphorus and calcium metabolism parameters, including urine calcium concentration, in patients with EBC treated with adjuvant chemotherapy. Importantly, although multiple factors modulate urine calcium concentration, its increase is classically considered as a contra-indication for vitamin D supplementation, because it could indicate a biological overdose of this vitamin. Therefore, before testing higher vitamin $\mathrm{D}$ and calcium dosages in this population, it is important to monitor the modification of calcium and vitamin $\mathrm{D}$ parameters and calcium urinary excretion during chemotherapy, associated or not with VD supplementation, to better understand the consequences of adjuvant treatments on this metabolic pathway.

The aim of this prospective study was to analyze changes in vitamin $\mathrm{D}$ and calcium metabolism parameters during adjuvant chemotherapy in patients with EBC, and especially the changes in calcium urinary excretion (primary objective).

\section{Methods}

\section{Study design}

CALCIOBS was an open-label non-randomized monocentric observational study carried out in our comprehensive cancer center between December 2015 and May 2017 to evaluate vitamin D and calcium parameters in patients with EBC treated with adjuvant chemotherapy. This study was approved by the local ethics committee (CPP Mediterannée Sud) and the national review board (ANSM, number 2014A01454-43). All patients provided a written informed consent prior to participation in the study. The study was performed in accordance with the Good Clinical Practices Requirements and the Helsinki Declaration.

\section{Patients}

Inclusion criteria were: $\geq 18$-year-old patients with $\mathrm{EBC}$, with Eastern Cooperative Oncology Group (ECOG) score of 0 or 1 , and programmed to receive six cycles of adjuvant chemotherapy. The main exclusion criteria were: metastatic disease, another cancer treated in the previous 3 years, contra-indication to calcium or cholecalciferol administration (severe allergic reactions to vitamin D or calcium supplementation or to excipients, diseases or conditions that cause hypercalcemia and/or hypercalciuria, calcium nephrolithiasis, tissue calcification, hypervitaminosis D), significant comorbidities (e.g. uncontrolled endocrine disease, pre-existing disorder in the phosphorus-calcium balance in the last 3 years, osteopenia or osteoporosis requiring treatment with calcium and vitamin D treatment), and any concomitant treatment with experimental products.

\section{Endpoints and other assessments}

The primary endpoint was the percentage of patients with hypercalciuria between the first day of the first adjuvant chemotherapy cycle (D1C1) and the first day of the last adjuvant chemotherapy cycle (D1C6), as reported by the clinician at the study end. The secondary endpoints were: (1) baseline vitamin D and calcium parameters, (2) percentage of patients with vitamin D normalization at D1C6 in the sub-population of patients with vitamin $\mathrm{D}$ insufficiency at baseline who received calcium and vitamin D supplementation (as reported by the clinician at the study end or as serum level $\geq 30 \mathrm{ng} /$ $\mathrm{mL}$ at DIC6), (3) changes in vitamin $\mathrm{D}$ and calcium parameters between D1C1 and D1C6, (4) predictive value of baseline biomarkers on baseline vitamin $\mathrm{D}$ level, and (5) predictive value of baseline variables on hypercalciuria occurrence.

At inclusion, serum vitamin D levels and the following calcium parameters were evaluated: blood levels of calcium, phosphorus, albumin, urea, creatinine and parathyroid hormone (PTH), as well as 24-h urinary calcium excretion. These parameters were then assessed at day 1 of each new chemotherapy cycle. In patients with baseline vitamin D insufficiency, prescription of calcium and vitamin D supplementation at the currently recommended doses ( $1 \mathrm{~g}$ and 400-500 IU per day, respectively) was left to the investigator's discretion $[9,11,13]$.

Vitamin D insufficiency was defined as a serum vitamin D level lower than $30 \mathrm{ng} / \mathrm{mL}(75 \mathrm{nmol} / \mathrm{L})$. The thresholds of continuous variables were based on the median of the study population; the normal/abnormal status of biological variables with a validated range was based on the local standard cut-offs (calcium: 2.15-2.5 mmol/l; phosphorus: 0.81-1.45 mmol/l; PTH: 15-65 ng/ L). Hypercalciuria was defined as a 24-h urinary calcium level $>7 \mathrm{mmol}$. 


\section{Statistical analyses}

All the analyses were done on the evaluable population, defined as the eligible patients who completed the six cycles of chemotherapy or who withdrawn from the study after the occurrence of hypercalciuria. Based on a hypercalciuria frequency of 50\% [14], a sample size of 82 patients gave a precision expressed by a two-sided $95 \%$ confidence interval (CI) width of $21.6 \%$. Descriptive statistics were performed in the whole populations and in the two groups (sufficient and insufficient vitamin D at baseline). Baseline characteristics were described as median and range (quantitative variables) and number of observations and percentages (qualitative variables). The number of missing values was reported and the percentages were calculated excluding missing values (unless otherwise specified). Quantitative variables were compared with the Kruskal-Wallis test by ranks, and qualitative variables with the chi-square or Fisher's exact test (when $n<5$ ). The 95\% CI for the primary endpoint was calculated using a logit transform. The laboratory parameter changes were described using boxplots at each chemotherapy cycle in the whole population and in each group. Additional analyses were performed using linear mixed models with random intercept and slope coefficients to predict the mean trajectories of the biological parameters in each group and to test time-effects and trajectory differences between groups. Logistic regressions were used to determine which baseline laboratory parameters were associated with baseline vitamin D deficiency and which baseline clinical characteristics and laboratory parameters were associated with hypercalciuria occurrence. All tests were two-sided and $p$-values $<0.05$ were considered as statistical significant. All analyses were performed using the Stata software (version 13.0).

\section{Results}

\section{Baseline patients' characteristics}

Between November 2015 and May 2017, 95 patients were prospectively included in the study. Among them, 13 patients were excluded from the analysis due to consent withdrawal $(n=8)$, metastatic disease $(n=3)$, no fulfillment of the study procedures $(n=1)$, and toxicity leading to chemotherapy discontinuation $(n=1)$. Therefore, the primary endpoint could be evaluated in 82 patients. The median follow-up was 17.3 weeks (range: 15.3-23.1).

The patients' median age was 53 years (range: 20-71) (Table 1). At baseline, 35 (43.2\%) patients were premenopausal, and $46(56.8 \%)$ post-menopausal $(n=1$ missing data). Most tumors were classified as stage I or II (91.3\%). Moreover, 72 tumors (87.8\%) were hormone receptor-positive, 10 (12.3\%) HER2-positive, and 7 (8.5\%) were triple negative. Overall, 79 patients $(96 \%)$ received anthracycline and taxane-based sequential chemotherapy of six cycles. Trastuzumab was administered in addition to chemotherapy to 11 patients (13.4\%). The median treatment period was 15 weeks (range: 14.9-18.7).

The median baseline vitamin $\mathrm{D}$ concentration was $20.7 \mathrm{ng} / \mathrm{mL}$ (range: $2.9-55$ ). Considering a threshold of $30 \mathrm{ng} / \mathrm{mL}, 66(80.5 \%)$ patients presented vitamin D insufficiency (median vitamin D value: $19.2 \mathrm{ng} / \mathrm{mL}$, range: 2.9-29.9), and 16 (19.5\%) patients did not (median vitamin D value: $37.5 \mathrm{ng} / \mathrm{mL}$, range: $30.2-55]$. Moreover, nine $(11 \%)$ patients received calcium and/or vitamin D supplementation: five received both, one only calcium, and three only vitamin $\mathrm{D}$. The baseline status of the assessed laboratory parameters, including PTH, calcium and phosphorus, was not correlated with vitamin D baseline insufficiency (Tables 1 and 2).

\section{Hypercalciuria occurrence during adjuvant chemotherapy: primary endpoint}

At baseline, hypercalciuria was detected in 11 patients (15\%). During adjuvant chemotherapy (between D1C1 and D1C6), hypercalciuria was observed in 29 of the 82 evaluable patients (35.4\%) [95\% CI: 25.6-46.5] (Table 3). Its frequency was not different in patients with and without baseline vitamin D sufficient concentration: $37.5 \%$ (95\% CI: 16.1-65.2) versus 34.8\%, (95\% CI: 24.1-47.4) $(p=0.8)$ (Table 3). Similarly, hypercalciuria occurrence was not different in patients with and without calcium and/or vitamin D supplementation (37.5\% [95\% CI: 8.779.2] versus $34.5 \%$ [95\% CI: 23.1-47.9], respectively; $p=$ $0.7)$, and in pre-menopausal and post-menopausal patients (34.3\% [95\% CI: $20-52.1]$ versus $34.8 \%$ [95\% CI: 22.1-50], respectively; $p=0.4$ ) (Table 4).

Hypercalciuria was more frequently detected in patients receiving docetaxel than paclitaxel ( $44 \%$ versus $21.4 \%, p=0.036$ ). No hypercalciuria was reported in patients treated with methotrexate-based chemotherapy $(n=3)$. Considering the 24-h urinary calcium level during adjuvant chemotherapy, the cumulative number of patients who developed hypercalciuria (24-h urinary calcium level $>7 \mathrm{mmol}$ ) increased linearly with the number of chemotherapy cycles (Fig. 1). Specifically, 13.4\% of patients developed hypercalciuria during the first cycle and the cumulative rate at treatment end was $42 \%$ (Fig. 1).

\section{Blood parameters of the vitamin D - calcium metabolism} The serum levels of vitamin D, PTH, phosphorus and calcium, from D1C1 to D1C6, are presented in Fig. 2 and supplementary data. At treatment end, the median vitamin D levels were $20 \mathrm{ng} / \mathrm{mL}$ (versus $20.7 \mathrm{ng} / \mathrm{mL}$ at baseline) in the whole population, $29.5 \mathrm{ng} / \mathrm{mL}$ (range: $20-39$ ) in the vitamin D sufficient group, and $17 \mathrm{ng} / \mathrm{mL}$ in the vitamin D insufficient group (range: 9-37.4). Although the vitamin D level was significantly different between groups 
Table 1 Patients'demographic, clinical and histological characteristics. Patients were divided in two groups: vitamin D sufficient and insufficient using the baseline serum vitamin D level cut-off of $30 \mathrm{ng} / \mathrm{mL}(75 \mathrm{nmol} / \mathrm{L})$

\begin{tabular}{|c|c|c|c|c|c|c|c|}
\hline \multirow{2}{*}{ DEMOGRAPHIC DATA } & \multicolumn{2}{|c|}{$\begin{array}{l}\text { Vitamin D Sufficient } \\
(n=16)\end{array}$} & \multicolumn{2}{|c|}{$\begin{array}{l}\text { Vitamin D Insufficient } \\
(n=66)\end{array}$} & \multicolumn{2}{|c|}{$\begin{array}{l}\text { Total } \\
(n=82)\end{array}$} & \multirow[t]{2}{*}{$p$-value } \\
\hline & & & & & & & \\
\hline Age (years), median [range] & 55 & [20-68] & 52.5 & {$[35-71]$} & 53 & {$[20-71]$} & 0.6 \\
\hline \multicolumn{8}{|l|}{ Menopausal status, n (\%) } \\
\hline Pre-menopausal & 6 & (37.5) & 29 & (44.6) & 35 & $(43.2)$ & \multirow[t]{3}{*}{0.6} \\
\hline Post-menopausal & 10 & $(62.5)$ & 36 & (55.4) & 46 & (56.8) & \\
\hline Missing & 0 & & 1 & & 1 & & \\
\hline \multicolumn{8}{|l|}{ CLINICAL DATA } \\
\hline \multicolumn{8}{|l|}{ ECOG score, $\mathrm{n}(\%)$} \\
\hline 0 & 16 & (100) & 59 & $(89.4)$ & 75 & $(91.5)$ & \multirow[t]{2}{*}{0.3} \\
\hline 1 & 0 & (0) & 7 & (10.6) & 7 & (8.5) & \\
\hline Weight $(\mathrm{kg})$, median [range] & 62 & [48-88] & 64.5 & {$[40-95]$} & 64 & {$[40-95]$} & 0.7 \\
\hline Height $(\mathrm{cm})$, median [range] & 164 & {$[157-170]$} & 161 & [149-178] & 162.5 & [149-178] & 0.3 \\
\hline BSA $\left(\mathrm{m}^{2}\right)$, median [range] & 1.71 & [1.46-1.93] & 1.71 & {$[1.32-2.06]$} & 1.71 & {$[1.32-2.06]$} & 0.9 \\
\hline \multicolumn{8}{|l|}{ BMI } \\
\hline$<25$ & 10 & (62.5) & 36 & (54.5) & 46 & $(56.1)$ & \multirow[t]{2}{*}{0.6} \\
\hline$\geq 25$ & 6 & (37.5) & 30 & $(45.5)$ & 36 & $(43.9)$ & \\
\hline \multicolumn{8}{|l|}{ HISTOLOGICAL DATA } \\
\hline \multicolumn{8}{|l|}{ Histological grade, n (\%) } \\
\hline 1 & 0 & (0) & 2 & (3.0) & 2 & (2.5) & \multirow[t]{3}{*}{0.7} \\
\hline 2 & 8 & (50) & 39 & $(59.1)$ & 47 & (57.3) & \\
\hline 3 & 8 & (50) & 25 & (37.9) & 33 & $(40.2)$ & \\
\hline \multicolumn{8}{|l|}{ Perivascular invasion, $\mathrm{n}(\%)$} \\
\hline No & 10 & (62.5) & 48 & (72.7) & 58 & $(70.7)$ & \multirow[t]{2}{*}{0.5} \\
\hline Yes & 6 & (37.5) & 18 & (27.3) & 24 & (29.3) & \\
\hline \multicolumn{8}{|l|}{ Estrogen receptor, n (\%) } \\
\hline$<10 \%$ & 1 & $(6.2)$ & 9 & (13.6) & 10 & $(12.2)$ & \multirow[t]{2}{*}{0.7} \\
\hline$\geq 10 \%$ & 15 & (93.8) & 57 & (86.4) & 72 & $(87.8)$ & \\
\hline \multicolumn{8}{|l|}{ Progesterone receptor, n (\%) } \\
\hline$<10 \%$ & 3 & $(18.7)$ & 18 & (27.3) & 21 & (25.6) & \multirow[t]{2}{*}{0.7} \\
\hline$\geq 10 \%$ & 13 & (81.3) & 48 & (72.7) & 61 & $(74.4)$ & \\
\hline \multicolumn{8}{|l|}{ HER2 +, n (\%) } \\
\hline No & 14 & (87.5) & 57 & $(87.7)$ & 71 & $(87.7)$ & \multirow[t]{3}{*}{1} \\
\hline Yes & 2 & $(12.5)$ & 8 & (12.3) & 10 & (12.3) & \\
\hline Missing & 0 & & 1 & & 1 & & \\
\hline Triple negative, $n(\%)$ & & & & & & & \\
\hline No & 15 & (93.8) & 60 & $(90.9)$ & 75 & (91.5) & 1 \\
\hline Yes & 1 & $(6.2)$ & 6 & $(9.1)$ & 7 & (8.5) & \\
\hline IJCC 2016 staging, n (\%) & & & & & & & \\
\hline । & 9 & (56.3) & 21 & (32.8) & 30 & (37.5) & 0.5 \\
\hline$\| \mathrm{A}$ & 5 & $(31.2)$ & 21 & (32.8) & 26 & (32.5) & \\
\hline$\| \mathrm{B}$ & 2 & (12.5) & 15 & (23.4) & 17 & (21.3) & \\
\hline$\| \mathrm{A}$ & 0 & $(0.0)$ & 6 & $(9.4)$ & 6 & $(7.5)$ & \\
\hline IIIC & 0 & $(0.0)$ & 1 & (1.6) & 1 & $(1.2)$ & \\
\hline Missing & 0 & & 2 & & 2 & & \\
\hline
\end{tabular}


Table 2 Baseline serum levels of vitamin D, calcium, phosphorus, albumin, urea, creatinine and parathyroid hormone (PTH)

\begin{tabular}{|c|c|c|c|c|c|c|c|}
\hline \multirow[b]{2}{*}{ Albumin (g/L), median [range] } & \multicolumn{2}{|c|}{$\begin{array}{l}\text { Vitamin D Sufficient } \\
(n=16)\end{array}$} & \multicolumn{2}{|c|}{$\begin{array}{l}\text { Vitamin D Insufficient } \\
(n=66)\end{array}$} & \multicolumn{2}{|c|}{$\begin{array}{l}\text { Total } \\
(n=82)\end{array}$} & \multirow{2}{*}{$\frac{\boldsymbol{p} \text {-value }}{0.2}$} \\
\hline & 45 & {$[40-51]$} & 44 & [37-53] & 44 & {$[37-53]$} & \\
\hline Missing & 0 & & 1 & & 1 & & \\
\hline PTH (ng/mL), median [range] & 38 & [17-61] & 42 & {$[13.5-124]$} & 42 & [13.5-124] & 0.2 \\
\hline Missing & 2 & & 3 & & 5 & & \\
\hline \multicolumn{8}{|l|}{ PTH, n (\%) } \\
\hline Normal & 14 & $(100)$ & 55 & $(87.3)$ & 69 & $(89.6)$ & 0.3 \\
\hline Abnormal & 0 & $(0)$ & 8 & $(12.7)$ & 8 & $(10.4)$ & \\
\hline Missing & 2 & & 3 & & 5 & & \\
\hline Calcium (mmol/L), median [range] & 2.42 & {$[2.25-2.84]$} & 2.39 & {$[2.15-2.56]$} & 2.39 & {$[2.15-2.84]$} & 0.1 \\
\hline Missing & 0 & & 2 & & 2 & & \\
\hline \multicolumn{8}{|l|}{ Calcium, n (\%) } \\
\hline Normal & 13 & $(81.3)$ & 60 & $(93.7)$ & 73 & $(91.3)$ & 0.1 \\
\hline Abnormal & 3 & $(18.7)$ & 4 & $(6.3)$ & 7 & $(8.7)$ & \\
\hline Missing & 0 & & 2 & & 2 & & \\
\hline Phosphorus (mmol/L), median [range] & 1 & {$[0.88-1.29]$} & 1 & {$[0.65-1.61]$} & 1 & {$[0.65-1.61]$} & 0.7 \\
\hline Missing & 0 & & 6 & & 6 & & \\
\hline \multicolumn{8}{|l|}{ Phosphorus (N) } \\
\hline Normal & 16 & (100) & 53 & $(88.3)$ & 69 & $(90.8)$ & 0.3 \\
\hline Abnormal & 0 & (0) & 7 & $(11.7)$ & 7 & $(9.2)$ & \\
\hline Missing & 0 & & 6 & & 6 & & \\
\hline Urea (mmol/L), median [range] & 4.5 & {$[2.9-8]$} & 4.7 & {$[2.2-8.2]$} & 4.7 & {$[2.2-8.2]$} & 0.9 \\
\hline Missing & 1 & & 6 & & 7 & & \\
\hline Creatinine $(\mu \mathrm{mol} / \mathrm{L})$, median [range] & 63 & {$[50-102]$} & 63 & [37-91] & 63 & {$[37-102]$} & 0.4 \\
\hline Missing & 0 & & 1 & & 1 & & \\
\hline $25 \mathrm{OH}$ vit $\mathrm{D}(\mathrm{ng} / \mathrm{mL})$, median [range] & 37.5 & [30.2-55] & 19.2 & {$[2.9-29.9]$} & 20.65 & {$[2.9-55]$} & $<0.001$ \\
\hline Missing & 0 & & 0 & & 0 & & \\
\hline
\end{tabular}

during chemotherapy ( $p<0.001$ for each cycle), $50 \%$ of patients (7/16; $n=2$ missing data) with baseline vitamin $\mathrm{D}$ sufficiency displayed vitamin D insufficiency at treatment end. The linear mixed model analysis found a significant decrease of the mean vitamin D level in the vitamin D sufficient group that was estimated at $1.4 \mathrm{ng} / \mathrm{mL}$ between cycles (slope estimate $=-1.4, p<0.001$ ) (Fig. 3). Among the 66 patients with insufficient vitamin D level at baseline, 5 corrected their vitamin $\mathrm{D}$ level with supplementation (7.8\%, $n=2$ missing data).

Serum PTH concentration was significantly different between the vitamin D sufficient and insufficient groups at C1 $(p=0.044)$ and C2 $(p=0.025)$. PTH level seemed to increase during chemotherapy compared with baseline (Fig. 2A). The linear mixed model analysis highlighted a significant increase of the mean PTH level during chemotherapy in both groups (estimated at $3.8 \mathrm{ng} / \mathrm{mL}$ between cycles, $p<0.001$ ).

Serum calcium level during chemotherapy was lower in the vitamin D insufficient group than in the sufficient group (Fig. 2B), but this difference was not significant. Unlike PTH concentration, the mean calcium level significantly decreased $(p<0.02)$ during treatment (estimated at $0.01 \mathrm{mmol} / \mathrm{L}$ between cycles in the vitamin $\mathrm{D}$ sufficient group, but without significant difference compared with the vitamin D insufficient group).

Serum phosphorus concentration was lower in the vitamin $\mathrm{D}$ insufficient than sufficient group at $\mathrm{C} 1(p=$ $0.018)$, but not at $\mathrm{C} 2$ and $\mathrm{C} 3(p<0.10)$ (Fig. 2B). The linear mixed models analysis confirmed the difference in phosphorus concentration between groups $(p=0.042)$, with an estimated mean phosphorus concentration difference of $0.07 \mathrm{mmol} / \mathrm{L}$ in the vitamin $\mathrm{D}$ insufficient vs. sufficient group.

\section{Baseline factors associated with baseline vitamin D insufficiency}

No baseline laboratory parameter was significantly associated with baseline vitamin D insufficiency, although a 
Table 3 Occurrence of hypercalciuria during chemotherapy in patients with vitamin D sufficient and insufficient levels, using the baseline serum vitamin D level cut-off of $30 \mathrm{ng} / \mathrm{mL}(75 \mathrm{nmol} / \mathrm{L})$

\begin{tabular}{|c|c|c|c|c|c|c|c|}
\hline & \multicolumn{2}{|c|}{ Sufficient $(N=16)$} & \multicolumn{2}{|c|}{ Insufficient $(N=66)$} & \multicolumn{2}{|c|}{ Total $(N=82)$} & \multirow[b]{2}{*}{$p$-value } \\
\hline & $\mathrm{N}$ & $\%[95 \% \mathrm{Cl}]$ & $\mathrm{N}$ & $\%[95 \% \mathrm{Cl}]$ & $\mathrm{N}$ & $\%[95 \% \mathrm{Cl}]$ & \\
\hline \multicolumn{8}{|c|}{ Hypercalciuria } \\
\hline No & 10 & 62.5 [34.8-83.9] & 43 & 65.2 [52.6-75.9] & 53 & $64.6[53.5-74.4]$ & 0.8 \\
\hline Yes & 6 & $37.5[16.1-65.2]$ & 23 & 34.8 [24.1-47.4] & 29 & 35.4 [25.6-46.5] & \\
\hline
\end{tabular}

trend towards a correlation between high calcium serum concentration and lower risk of baseline vitamin $\mathrm{D}$ insufficiency (Odds Ratio, OR =0.003) was observed ( $p=$ 0.051). None of the clinical parameters (e.g. weight, body mass index, age, and menopausal status) was significantly associated with baseline vitamin D insufficiency.

Predictive value of baseline clinical-pathological variables on hypercalciuria occurrence during adjuvant chemotherapy

In univariate analysis, larger body surface area and lower albumin level at baseline were significantly correlated with hypercalciuria occurrence during adjuvant chemotherapy (body surface area $\geq 1.7$ vs. $<1.7$, OR $=2.68 ; p=$ 0.04 and serum albumin level $\geq 44 \mathrm{~g} / \mathrm{L}$ vs. $<44 \mathrm{~g} / \mathrm{L}, \mathrm{OR}=$ $3.055 ; p=0.023)$.

\section{Discussion}

This prospective monocentric study evaluated the changes in blood and urinary vitamin D and calcium concentrations in patients with EBC during adjuvant chemotherapy. Our study confirmed the high frequency $(80.5 \%)$ of baseline vitamin D insufficiency, in accordance with the literature. Crew et al. reported a $74 \%$ rate of vitamin D insufficiency before adjuvant chemotherapy in a cohort of 103 patients with EBC [7]. Similarly, our team found a baseline vitamin D insufficiency frequency of $79.4 \%$ in a previous cohort of patients with EBC receiving neoadjuvant chemotherapy, a rate that increased to

Table 4 Occurrence of hypercalciuria according to calcium and/ or vitamin D supplementation (top) and baseline menopausal status (bottom)

\begin{tabular}{|c|c|c|c|c|c|}
\hline \multicolumn{6}{|c|}{ Vitamin D and/or calcium supplementation $(N=66)$} \\
\hline & \multicolumn{2}{|c|}{ Yes $(n=9)$} & \multicolumn{2}{|c|}{ No $(n=58)$} & $p$-value \\
\hline \multicolumn{6}{|c|}{ Hypercalciuria } \\
\hline No & 5 & $62.5[20.8-91.3]$ & 38 & $65.5[52.1-76.9]$ & 0.7 \\
\hline Yes & 3 & $37.5[8.7-79.2]$ & 20 & $34.5[23.1-47.9]$ & \\
\hline \multicolumn{6}{|c|}{ Baseline Menopausal status $(N=81)$} \\
\hline & \multicolumn{2}{|c|}{ Yes $(n=46)$} & \multicolumn{2}{|c|}{ No $(n=35)$} & \\
\hline \multicolumn{6}{|c|}{ Hypercalciuria } \\
\hline No & 30 & $65.2[50-77.9]$ & 23 & $65.7[47.9-80]$ & 0.4 \\
\hline Yes & 16 & $34.8[22.1-50]$ & 12 & $34.3[20-52.1]$ & \\
\hline
\end{tabular}

97.4\% at treatment end. In this previous study, we also showed that vitamin D insufficiency was associated with bone metabolism imbalance: the levels of calcium and RANK ligand (RANKL) (a major stimulating factor of osteoclast formation and survival) decreased during chemotherapy, and those of osteoprotegerin (OPG), a protein that inhibits osteoclast recruitment, increased. The consequent decrease of the RANKL/OPG ratio suggests a dysregulation of a functional regulatory mechanism of bone turn-over [5]. In the present study, we confirmed, in the adjuvant setting, the significant decrease of serum vitamin D levels during chemotherapy, especially in the group with baseline vitamin D sufficiency. Indeed, $50 \%$ of patients in this group had vitamin D deficiency at the study end. Overall, $84.6 \%$ of the whole population presented vitamin D insufficiency at the study end (Supplementary Table 1). Thus, vitamin D insufficiency was consistently and frequently associated with breast cancer diagnosis and increased (frequency and severity) during chemotherapy treatment. However, baseline vitamin D insufficiency was not associated with any of the baseline clinical and laboratory variables. This vitamin $\mathrm{D}$ insufficiency may strongly increase the risk of skeletal morbidity and other calcium-related diseases.

The recommended daily calcium and vitamin D supplementation (200 to $400 \mathrm{IU}$ of vitamin D per day and $1200 \mathrm{mg}$ of calcium per day) is not enough, in most cases, to normalize the serum vitamin D levels during chemotherapy $[15,16]$. Our team previously reported, in a prospective randomized trial, a $12 \%$ rate of vitamin $\mathrm{D}$ level normalization with the classical daily supplementation, which is comparable to the $7.8 \%$ rate observed in the present study. Altogether, these data indicate that vitamin $\mathrm{D}$ insufficiency in this population requires higher vitamin $\mathrm{D}$ and calcium doses to increase the rate of vitamin D level normalization to $30 \%$, as shown in our previous study [12]. Previous studies reported an association between low baseline vitamin D levels and poor response to neoadjuvant chemotherapy. The retrospective study by Chiba et al. showed that baseline vitamin $\mathrm{D}$ deficiency increases by 2.65 times the risk of not reaching a pathological complete response after neoadjuvant chemotherapy [17]. This link between vitamin D levels and response to treatment [18] might strengthen the clinical interest to achieve sufficient vitamin D levels in patients with EBC during treatment. However, due to 

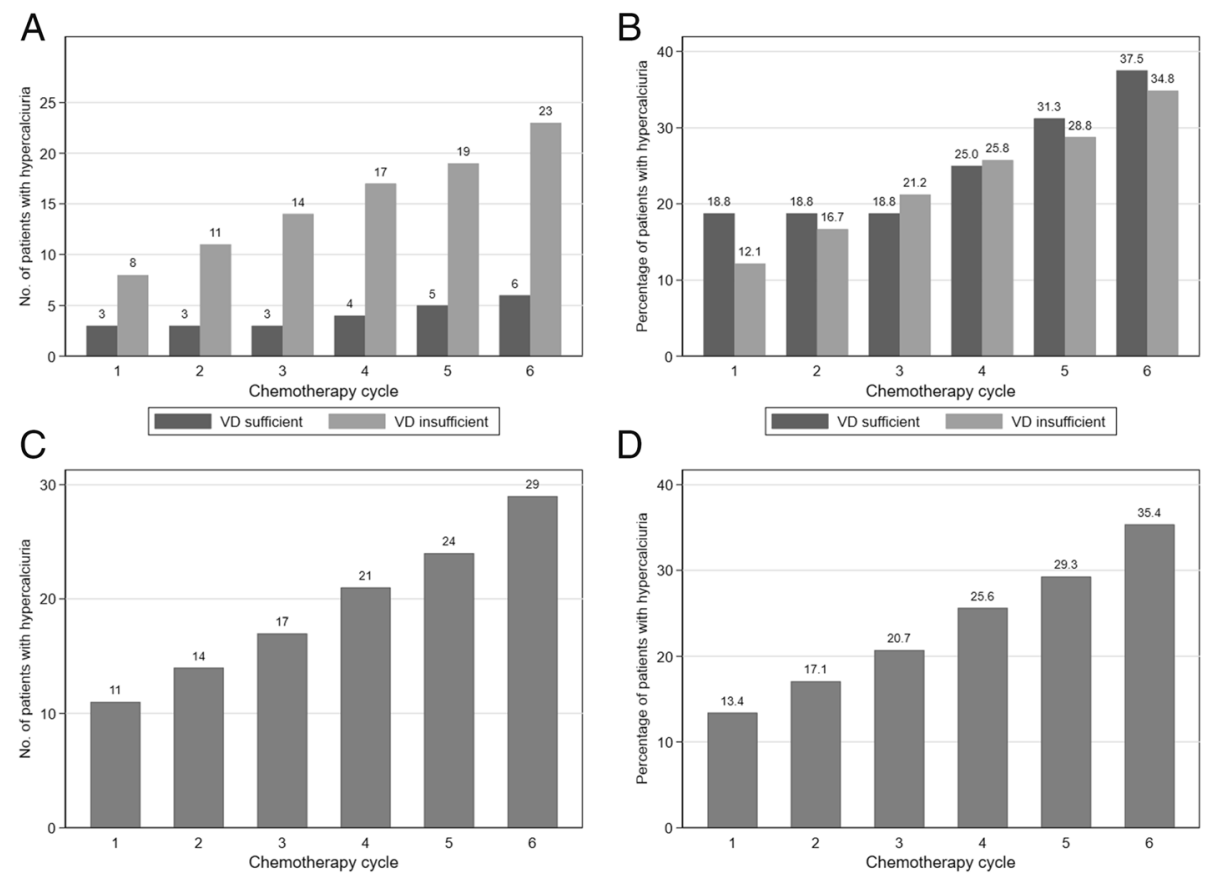

Fig. 1 Cumulative number ( $\mathbf{A}$ and $\mathbf{C}$ ) and percentage (B and $\mathbf{D}$ ) of patients with EBS with at least one occurrence of hypercalciuria during chemotherapy. In $\mathbf{A}$ and $\mathbf{B}$, patients were divided in two groups (vitamin D sufficient, $n=16$, and insufficient, $n=66$ ) using the baseline serum vitamin D level cut-off of $30 \mathrm{ng} / \mathrm{mL}$ ( $75 \mathrm{nmol} / \mathrm{L}) . \mathbf{C}$ and $\mathbf{D}$ present the same data for the whole population $(n=82)$

the multiple interactions of vitamin D with breast cancer outcome, kidney cancer clearance and the potential side effects of hypervitaminosis $\mathrm{D}$, a better understanding of calcium metabolism is needed before increasing vitamin D supplementation in clinical practice. Indeed, the safety of higher vitamin D doses must be evaluated as required by the Health Regulatory Services and Ethics Committees, especially concerning hypercalciuric events, a potential side effect of vitamin D supplementation. Therefore, here, we evaluated changes in urine calcium levels in patients taking or not vitamin D supplementation during $\mathrm{EBC}$ treatment. Urinary calcium excretion is an important biomarker for understanding the phosphorus-calcium metabolism, and the 24-h urinary calcium excretion is routinely used to guide mineral supplementation in Europe [19]. However, there was no data on this parameter during chemotherapy, thus limiting the generalization of high dose vitamin D supplementation in these patients. In the present study, we detected baseline hypercalciuria in $15 \%$ of patients, in agreement with data in the general population $(10 \%)$ [20]. Our results highlighted that hypercalciuria is frequent during chemotherapy (35\%), but always clinically asymptomatic. The absence of symptoms might be due to the fact that urine calcium elevation in our patients was generally moderate, and clinical symptoms might appear only with chronic hypercalciuria (i.e. years) or with extreme concentrations. Moreover, hypercalciuria has never been described in the natural history of breast cancer. We found that hypercalciuria occurrence was not correlated with baseline vitamin D levels and with calcium and vitamin D supplementation, in accordance with the results by Gallagher et al. [21]. In patients with EBC undergoing adjuvant chemotherapy, hypercalciuria might be explained by several factors in addition to chemotherapy. In a previous study, we showed that dysregulation of the osteoclast/osteoblasts balance [5] occurs concomitantly with the decrease of serum vitamin D levels. Also, chemotherapy can sometimes induce chemical menopause due to ovarian failure (in pre-menopausal women). Moreover, it has been shown that post-menopausal women develop hypercalciuria more frequently because of the menopause-induced changes in calcium balance [22], resulting in bone loss [23]. In our study, almost half of patients were pre-menopausal at baseline. Hypercalciuria occurred independently of the menopausal status; nevertheless, most pre-menopausal patients might have developed at least transient ovarian failure due to chemotherapy, which could have modified bone metabolism. Thus, long-term evaluation of bone mineral density in these patients would allow testing a possible correlation between low bone density and hypercalciuria. 

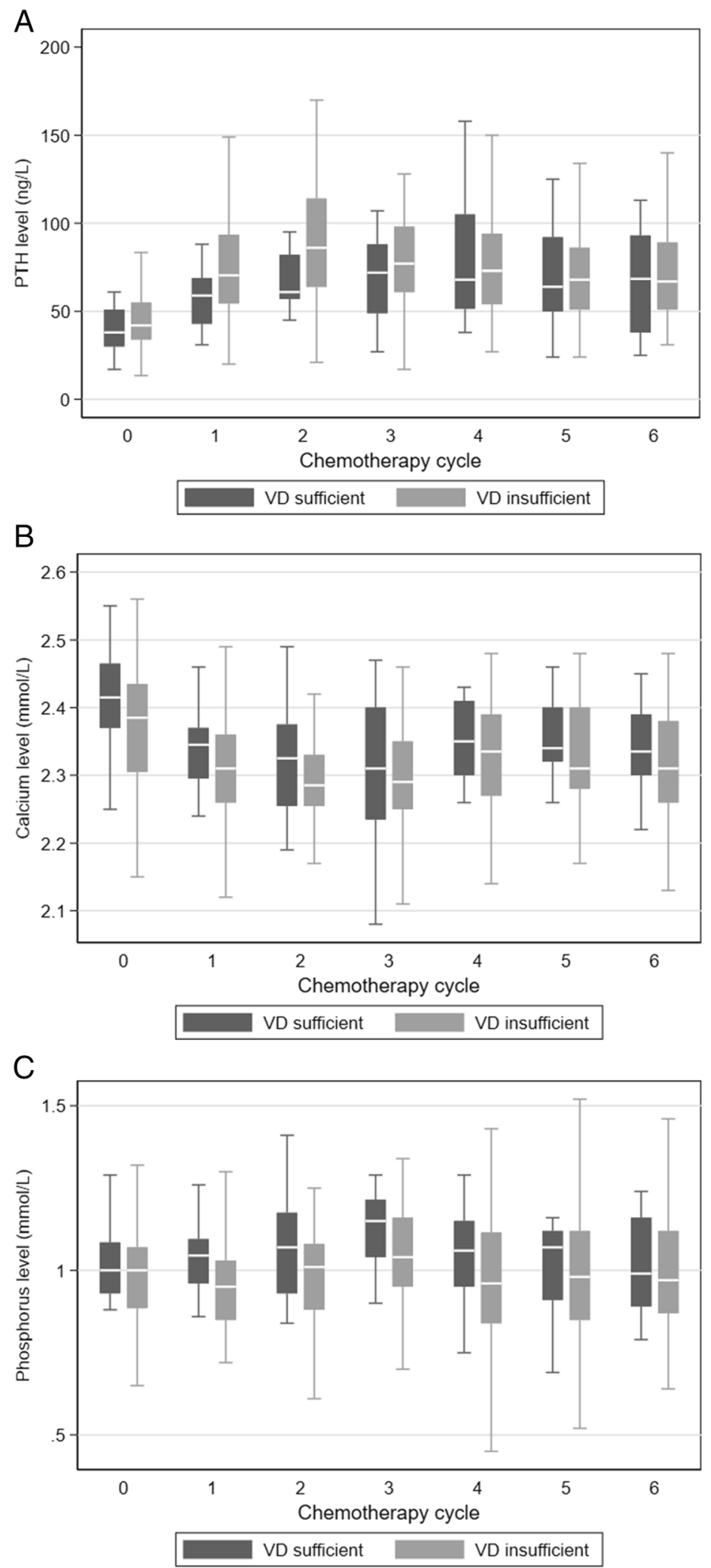

Fig. 2 PTH (A), calcium (B) and phosphorus (C) levels changes during chemotherapy according to the serum baseline vitamin D concentration. Patients were divided in two groups (vitamin D sufficient, $n=16$, and insufficient, $n=66$ ) using the baseline serum vitamin D level cut-off of $30 \mathrm{ng} / \mathrm{mL}(75 \mathrm{nmol} / \mathrm{L}$ ) 


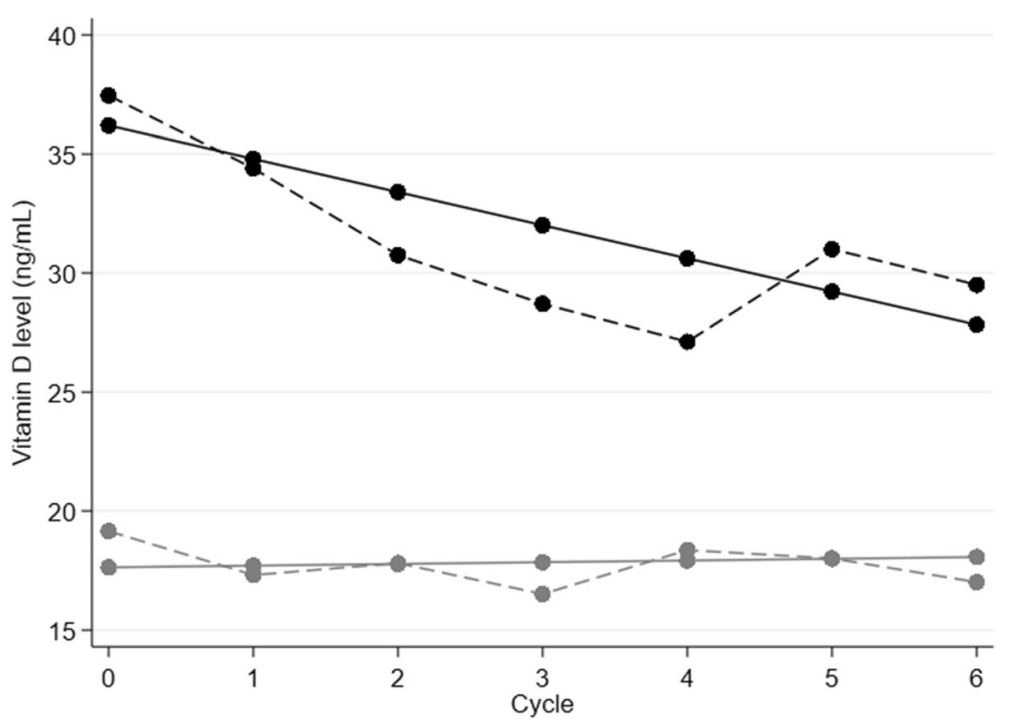

Fig. 3 Predicted (solid lines) and observed (dashed lines) vitamin D serum concentration during chemotherapy. Patients were divided in two groups: vitamin D sufficient ( $n=16$, black lines) and insufficient ( $n=66$, grey lines) using the baseline serum vitamin D level cut-off of $30 \mathrm{ng} / \mathrm{mL}(75 \mathrm{nmol} / \mathrm{L}$ )

Transient hypercalciuria also has been reported in association with concomitant treatments, such as corticosteroids that are often used in combination with chemotherapeutic agents (anthracyclines and taxanes) as anti-emetic and anti-allergic drugs [24]. Hypercalciuria is due to the decrease of calcium absorption by the digestive tube, and an increase in its renal excretion, especially in patients receiving methylprednisolone doses higher than $20 \mathrm{mg}$ per day. Calcium urinary level was not assessed at 6 months after chemotherapy completion in our study. Almost all patients received sequential chemotherapy (anthracyclines and taxanes), associated with systematic corticosteroids. Nevertheless hypercalciuria occurred more frequently in patients receiving docetaxel (44\%) than in those receiving paclitaxel (21.4\%), which might be explained by a higher cumulated dose of corticosteroids during the course of their treatment than in the paclitaxel group.

Finally, dietary changes, including those associated with chemotherapy, have been reported to induce hypercalciuria [22-26]. One limitation of the present study is the lack of dietary data from our patients during the study.

Although hypercalciuria had no clinical impact in our patients, it remains a classical contra-indication to vitamin D supplementation, and therefore the identification of baseline variables associated with hypercalciuria occurrence could allow the selection of patients with low hypercalciuria risk for high dose vitamin D supplementation. However, in our study, only the baseline body surface and serum albumin level were predictive of hypercalciuria occurrence. Data are scarce on predictive factors of hypercalciuria. Carvalho et al. found no correlation between body mass index and hypercalciuria in a cohort of post-menopausal women with osteoporosis [23], and Mente et al. showed a correlation between hypercalciuria and lower body mass index in a population of patients with kidney stone disease and hypercalciuria, as we previously described in our cohort of patients with breast cancer [18]. Thus, asymptomatic hypercalciuria appears to be a frequent, rarely predictable, and benign condition during adjuvant chemotherapy for EBV, and should not be a limitation to adequate vitamin D supplementation in this setting.

\section{Conclusions}

In this prospective study of vitamin $\mathrm{D}$ level and calcium metabolism changes in patients with EBC during adjuvant chemotherapy, hypercalciuria occurred in $35 \%$ of patients, but was always asymptomatic, independently of the vitamin D level and of calcium and vitamin D supplementation. Standard supplementation was safe but ineffective in our population. Urinary calcium levels does not seem relevant in patients with $\mathrm{EBC}$ receiving adjuvant chemotherapy, and should not be considered as an exclusion criterion for vitamin D insufficiency correction, considering the multiple negative effects of such deficiency.

\section{Abbreviations}

VD: Vitamin D; CT: Chemotherapy; D1C1: Day 1, Cycle 1; D1C6: Day 1, Cycle 6; EBC: Early Breast Cancer; HER2: Human EGF Receptor 2; RANKL: RANK ligand; OPG: Osteoprotegerin; ECOG: Eastern cooperative oncology group; Min: Minimum; Max: Maximum; PTH: Parathormone; IU: International unit: OR: Odds ratio 


\section{Supplementary Information}

The online version contains supplementary material available at https://doi. org/10.1186/s12885-021-08563-4.

Additional file 1: Figure S1. Vitamin D serum level changes during the six chemotherapy cycles in patients with baseline vitamin D sufficient $(n=16)$ and insufficient concentration $(n=66)$. Table S1. Vitamin D level changes during the six cycles of chemotherapy in patients with baseline sufficient and insufficient vitamin D concentration.

\section{Acknowledgements}

The authors thank Hélène de Forges, Ph.D. for substantial writing and editorial assistance. The authors thank Elisabetta Andermacher for english revision.

\section{Authors' contributions}

WJ designed the study. WJ and MM acquired the data. WJ, MV, and CT analyzed and interpreted the data. MV wrote the main manuscript. MV, WJ, $C T$, and HDF reviewed the manuscript for critical content. MV, NF, CT, SP, MM, Lise Roca, GR, Lobna Rifai, SG, VDH, WJ reviewed and approved the final manuscript.

\section{Funding}

Not Applicable.

\section{Availability of data and materials}

The data that support the findings of this study are available from the authors upon reasonable request.

\section{Declarations}

\section{Ethics approval and consent to participate}

This study was reviewed and approved by the Agence Nationale de Sécurité du Médicament et des produits de santé (ANSM) and the Comité de Protection des Personnes (CPP) Mediterannée Sud under the reference 2014A01454-43. All patients gave their written informed consent. The study was performed in accordance with the Good Clinical Practices Requirements and the Helsinki Declaration.

\section{Consent for publication}

Not applicable.

\section{Competing interests}

None.

\section{Author details}

'Department of Medical Oncology, Institut du Cancer de Montpellier (ICM), University of Montpellier, 208 avenue des Apothicaires, 34090 Montpellier, France. ${ }^{2}$ INSERM U1194 - IRCM, Montpellier, France. ${ }^{3}$ Biometrics Unit, Institut du Cancer de Montpellier (ICM), Univ. Montpellier, Montpellier, France. ${ }^{4}$ Clinical Research Center, Institut du Cancer de Montpellier (ICM), Univ. Montpellier, Montpellier, France. ${ }^{5}$ Department of Clinical Research and Innovation, Institut du Cancer de Montpellier (ICM), Univ. Montpellier, Montpellier, France. ${ }^{6}$ Department of Clinical Research and Innovation, Centre Hospitalier Universitaire de Nîmes, Nîmes, France.

\section{Received: 16 March 2021 Accepted: 18 June 2021}

\section{Published online: 15 July 2021}

\section{References}

1. Ferlay J, Soerjomataram I, Dikshit R, Eser S, Mathers C, Rebelo M, et al. Cancer incidence and mortality worldwide: sources, methods and major patterns in GLOBOCAN 2012. Int J Cancer. 2015;136(5):E359-86. https://doi. org/10.1002/ijc.29210.

2. Association of Breast Surgery at Baso. Surgical guidelines for the management of breast cancer. Eur J Surg Oncol J Eur Soc Surg Oncol Br Assoc Surg Oncol. 2009;35(Suppl 1):1-22.

3. Early Breast Cancer Trialists' Collaborative Group (EBCTCG). Comparisons between different polychemotherapy regimens for early breast cancer: meta-analyses of long-term outcome among 100000 women in 123 randomised trials. Lancet. 2012:379:432-44.

4. Piccart-Gebhart MJ, Procter M, Leyland-Jones B, Goldhirsch A, Untch M, Smith I, et al. Trastuzumab after adjuvant chemotherapy in HER2-positive breast cancer. N Engl J Med. 2005;353(16):1659-72. https://doi.org/10.1056/ NEJMoa052306.

5. Jacot W, Pouderoux S, Thezenas S, Chapelle A, Bleuse J-P, Romieu G, et al. Increased prevalence of vitamin $D$ insufficiency in patients with breast cancer after neoadjuvant chemotherapy. Breast Cancer Res Treat. 2012; 134(2):709-17. https://doi.org/10.1007/s10549-012-2084-7.

6. Mann GB, Kang YC, Brand C, Ebeling PR, Miller JA. Secondary causes of low bone mass in patients with breast cancer: a need for greater vigilance. $J$ Clin Oncol Off J Am Soc Clin Oncol. 2009;27(22):3605-10. https://doi.org/1 $0.1200 / J C O .2008 .20 .2549$

7. Crew KD, Shane E, Cremers S, McMahon DJ, Irani D, Hershman DL. High prevalence of vitamin $D$ deficiency despite supplementation in premenopausal women with breast cancer undergoing adjuvant chemotherapy. J Clin Oncol Off J Am Soc Clin Oncol. 2009;27(13):2151-6. https://doi.org/10.1200/JCO.2008.19.6162.

8. Imtiaz S, Siddiqui N, Raza SA, Loya A, Muhammad A. Vitamin D deficiency in newly diagnosed breast cancer patients. Indian J Endocrinol Metab. 2012 16(3):409-13. https://doi.org/10.4103/2230-8210.95684.

9. Cavalier E, Delanaye P, Chapelle J-P, Souberbielle J-C. Vitamin D: current status and perspectives. Clin Chem Lab Med. 2009;47(2):120-7. https://doi. org/10.1515/CCLM.2009.036.

10. Holick MF. Vitamin D deficiency. N Engl J Med. 2007;357(3):266-81. https:// doi.org/10.1056/NEJMra070553.

11. Vieth R, Bischoff-Ferrari H, Boucher BJ, Dawson-Hughes B, Garland CF, Heaney RP, et al. The urgent need to recommend an intake of vitamin D that is effective. Am J Clin Nutr. 2007;85(3):649-50. https://doi.org/10.1093/a jen/85.3.649.

12. Jacot W, Firmin N, Roca L, Topart D, Gallet S, Durigova A, et al. Impact of a tailored oral vitamin D supplementation regimen on serum 25 hydroxyvitamin D levels in early breast cancer patients: a randomized phase III study. Ann Oncol Off J Eur Soc Med Oncol. 2016;27(7):1235-41. https:// doi.org/10.1093/annonc/mdw145.

13. Vieth R. Vitamin D supplementation, 25-hydroxyvitamin D concentrations, and safety. Am J Clin Nutr. 1999:69(5):842-56. https://doi.org/10.1093/ajen/ 69.5.842.

14. Atkinson SA, Fraher L, Gundberg CM, Andrew M, Pai M, Barr RD. Mineral homeostasis and bone mass in children treated for acute lymphoblastic leukemia. J Pediatr. 1989;114(5):793-800. https://doi.org/10.1016/S0022-34 76(89)80138-6.

15. Leidig-Bruckner G, Roth HJ, Bruckner T, Lorenz A, Raue F, Frank-Raue K. Are commonly recommended dosages for vitamin D supplementation too low? Vitamin D status and effects of supplementation on serum 25hydroxyvitamin D levels--an observational study during clinical practice conditions. Osteoporos Int J Establ Result Coop Eur Found Osteoporos Natl Osteoporos Found USA. 2011;22(1):231-40. https://doi.org/10.1007/s00198010-1214-5.

16. Pubmeddev GJ et al. Dose response to vitamin D supplementation in postmenopausal women: a randomized trial. - PubMed - NCBI [Internet]. [cited 2019 Nov 15]. Available from: https://www.ncbi.nlm.nih.gov/ pubmed/22431675.

17. Chiba A, Raman R, Thomas A, Lamy P-J, Viala M, Pouderoux S, et al. Serum vitamin $D$ levels affect pathologic complete response in patients undergoing neoadjuvant systemic therapy for operable breast Cancer. Clin Breast Cancer. 2018;18(2):144-9. https://doi.org/10.1016/j.clbc.201 7.12.001.

18. Viala M, Chiba A, Thezenas S, Delmond L, Lamy P-J, Mott SL, et al. Impact of vitamin $D$ on pathological complete response and survival following neoadjuvant chemotherapy for breast cancer: a retrospective study. BMC Cancer. 2018;18(1):770. https://doi.org/10.1186/s12885-018-4686-x.

19. Monitoring of urinary calcium and phosphorus excretion in preterm infants: comparison of 2 methods. - PubMed - NCBI [Internet]. [cited 2020 Mar 26] Available from: https://www.ncbi.nlm.nih.gov/pubmed/24253368.

20. Hypercalciuria: Practice Essentials, Background, Pathophysiology [Internet]. [cited 2020 Mar 26]. Available from: https://emedicine.medscape.com/a rticle/2182757-overview

21. Gallagher JC, Smith LM, Yalamanchili V. Incidence of hypercalciuria and hypercalcemia during vitamin D and calcium supplementation in older 
women. Menopause N Y N. 2014;21(11):1173-80. https://doi.org/10.1097/ GME.0000000000000270

22. Giannini S, Nobile M, Dalle Carbonare L, Lodetti MG, Sella S, Vittadello G, et al. Hypercalciuria is a common and important finding in postmenopausal women with osteoporosis. Eur J Endocrinol. 2003;149(3):209-13. https://doi. org/10.1530/eje.0.1490209.

23. Carvalho M, Kulak CAM, Borba VZC. Prevalence of hypercalciuria in postmenopausal women with osteoporosis. Ara Bras Endocrinol Metabol. 2012;56(1):1-5. https://doi.org/10.1590/S0004-27302012000100001.

24. Duzen O, Erkoc R, Begenik H, Soyoral YU, Aldemir MN. The course of hypercalciuria and related markers of bone metabolism parameters associated with corticosteroid treatment. Ren Fail. 2012;34(3):338-42. https:// doi.org/10.3109/0886022X.2011.648596.

25. Damasio PCG, Amaro CRPR, Cunha NB, Pichutte AC, Goldberg J, Padovani CR, et al. The role of salt abuse on risk for hypercalciuria. Nutr J. 2011;10(1):3. https://doi.org/10.1186/1475-2891-10-3.

26. Garg A, Bonanome A, Grundy SM, Unger RH, Breslau NA, Pak CY. Effects of dietary carbohydrates on metabolism of calcium and other minerals in normal subjects and patients with noninsulin-dependent diabetes mellitus. J Clin Endocrinol Metab. 1990;70(4):1007-13. https://doi.org/10.1210/jcem70-4-1007.

\section{Publisher's Note}

Springer Nature remains neutral with regard to jurisdictional claims in published maps and institutional affiliations.

Ready to submit your research? Choose BMC and benefit from:

- fast, convenient online submission

- thorough peer review by experienced researchers in your field

- rapid publication on acceptance

- support for research data, including large and complex data types

- gold Open Access which fosters wider collaboration and increased citations

- maximum visibility for your research: over $100 \mathrm{M}$ website views per year

At $\mathrm{BMC}$, research is always in progress.

Learn more biomedcentral.com/submissions 